\title{
ESTIMATION OF SEISMIC MOTION AND DAMAGE TO STRUCTURES FOR NEW BULLET TRAINS
}

\author{
Yutaka Nakamura* and Hidehiko Abe**
}

Accepted for but not presented at the Third South Pacific Regional Conference on Earthquake Engineering, Wellington, May 1983.

\section{SYNOPSIS}

It is necessary to investigate the earthquake-resistance of existing railway structures against a supposed earthquake in order to implement earthquake-resistant reinforcement. This paper describes the method of predicting the degree of damage that may be caused by a supposed earthquake based on estimation of the surface earthquake motion. The paper will be of help for selection of the structures that require reinforcement and for determination of the extent of such reinforcement works.

\section{INTRODUCTION}

Earthquake-resistant reinforcement has been implemented for railway structures to prepare for the Tokai earthquake which is anticipated to occur in the near future. A reasonable way to reinforce structures against a supposed earthquake is first to investigate the earthquake-resistance of structures for selecting the structures that require reinforcement and then to implement the reinforcement that satisfies the requirement for strength. This requires an accurate assumption for the nature of the surface motion in the location of a railway which will be caused by the earthquake. Since a railway system is a serial system in the meaning that overall earthquake-resistance is controlled by the weakest structure in the system, high accuracy is needed for the evaluation of the earthquake-resistance. Therefore, the presumption for surface earthquake motion should also have a high accuracy. In the case of a railway, fortunately, relatively sufficient amount of information on the ground is available that is urgently necessary for the estimation of the earthquake motion. Effective use of such information makes it possible to more accurately estimate the surface earthquake motion.

This paper describes the detailed classification of ground with an emphasis being placed on the response characteristics of surface layer ground. An approach for predicting the surface earthquake motion based on such classification is also described. Further, a method to estimate the degree of damage from the earthquake motion assumed with this approach is examined.

\section{CONCEPT FOR SURFACE EARTHQUAKE MOTION PREDICTION METHOD}

Seismic waves radiated from a hypocentre propagate in a hard crust and reach a surface layer, where they are amplified or transformed during propagation as a surface earthquake motion. Therefore, by setting a so-called seismic basement at a

*Senior Researcher, Structure Laboratory, Railway Technical Research Institute, Japanese National Railways, Tokyo, Japan. **Director, Structure Design Office, Japanese National Railways, Tokyo,

surface layers (2). Based thereon, the
BULLETIN OF THE NEW ZEALAND NATIONAL SOCIETY FOR EARTHQUAKE ENGINEERING, VOL. 17, NO. 2, JUNE proper depth and assuming a wave incident on the basement, the surface earthquake motion spectrum is given by the product of the basement-incident spectrum and the vibration characteristics of the surface layer ground.

Therefore, the following procedures are proposed for the estimation of the surface earthquake motion:

(a) Classify the surface layer grounds along a railroad according to the similarity of the amplification characteristics.

(b) For each of the kinds of surface ground obtained above, determine the relationship between the maximum acceleration of the base ground and the maximum values of earthquake motion in the surface ground (referred to as the "response curve" hereinafter). Then estimate the maximum values of the surface ground motion in a particular location for a supposed earthquake.

No definite opinion is available for determining the layer in which the earthquake basement should be set. There is much argument about it. From an engineering point of view, it should be the region below which the dynamic nature can be considered to be little different. In actuality, however, it is arbitrarily set depending upon the purpose of the study and the data to be used. In this paper the earthquake basement is set in the layer that can be regarded as a support layer for structure foundation from an engineering point of view, such as alluvial gravel sand. If an influence on structures is considered, an accurate grasp of the motion of soft layers is required. Compared with soft layers, the support layer is sufficiently rigid and the amount of response from the region below this layer can be considered much smaller than that from the region above it. Therefore, in principle, a surface ground layer having the $\mathrm{N}$ value (1) of more than 50 and the $S$ wave velocity of more than $500 \mathrm{~m} / \mathrm{s}$ has been selected as the earthquake basement, including alluvial gravel.

Many researchers, including Dr Kanai, have made it clear that, in short period regions, the multiple reflection phenomenon of $\mathrm{SH}$ wave is the dominant factor that specifies the vibration characteristics of surface layers (2). Based thereon, the 
study of vibration characteristics is Iimited to the multiple reflection phenomenon in the horizontal layers in this paper. As the surface earthquake motions, shearing strain and shearing stress, etc are considered in addition to acceleration, velocity and displacement. Among much research that has been done with respect to the ground-incident acceleration wave used for determining a response curve, no definite one is available for the frequency region of $0.2 \mathrm{~Hz}$ to $5 \mathrm{~Hz}$, which is handled in this paper. Therefore, two kinds of incident waves are considered: relatively long-period predominant wave and short-period predominant wave. "Hachinohe" and "shin-Kikugawa" are selected from among the waves actually observed as such waves. "Hachinohe" is a relatively long-period type wave in which frequency component of $1 \mathrm{~Hz}$ or lower is predominant and was obtained by converting the NS component wave (3) observed at Hachinohe Port in the Tokachi-oki earthquake $(M=7.9)$ in 1968 into an incident wave on an earthquake basement (-17 m). "Shin-Kikugawa" is the EW component wave observed at the Shin-Kikugawa substation (Tokaido Shinkansen) in Izu-Ohshima-kinkai earthquake $(M=7.0)$ in 1978 and is a shortperiod type wave, in which $2 \mathrm{~Hz}$ to $5 \mathrm{~Hz}$ component is predominant. Figure 1 shows these waveforms and Fourier Spectra.

\section{GROUND CLASSIFICATION}

A classification method for surface layer ground is described here based on the geological data available to a section along Tokaido and Sanyo bullet train line (Shinkansen between Tokyo and Hakata, see Figure 2). This method can also be applied to any other areas.

For our purpose, geological data including soil pillars along the bullet train line were collected to make soil profiles of the section. Based on the data, ground along the railway line is classified, taking the similarity of the structure into consideration. As a result, ground between Tokyo and Hakata was classified into 1,647 except tunnels. The classified ground was then grouped into 446 types by comparing the soil pillars with the $\mathrm{N}$ value distribution for integrating the ground of similar layer construction and thickness, which is called First Ground Classification.

To analyse earthquake response of the ground for determining the response curve, iterative convergence calculation is performed for an equivalent linear response analysis by taking it into account that ground rigidity reduces due to the shearing strain. It is rather impractical since it requires a large amount of calculation to investigate the characteristics for 446 ground types obtained by the first ground classification. Therefore, integration of the first ground classification was intended according to the similarity of vibration characteristics of surface layer ground, which is called second classification.

\section{GROUND CLASSIFICATION BASED ON VIBRATION} CHARACTERISTICS

By giving layer thickness, density and $S$ wave velocity to each of the $446 \mathrm{kinds}$ of ground extracted by first classification, a horizontal multi-layer model was formed to obtain a transfer function $\mathrm{H}(\omega)$ of wave according to the multiple reflection theory of $\mathrm{SH}$ wave. The ground constants for modelling are determined from Table 1 by using the information on soil nature and $\mathrm{N}$ values. The propagation velocity of $\mathrm{S}$ wave, Vs $(=\sqrt{G / 0})$, shown in this table was determined from the data of PS logging performed for the vicinity of the section with correspondence to $\mathrm{N}$ values being investigated for each soil nature. The density was set based on the soil nature test data at the time of construction. The damping constant of each layer used in obtaining the transfer function $H(\omega)$ was set to be 1 percent for micro strain level in the order of

In general, the first order peak is relatively predominant to a great extent in the transfer function, which is in the converged state by equivalent linear iterative calculation. Therefore, to classify ground based on the earthquake response characteristics it is considered to be appropriate to pay attention to the first peak of the initial state transfer function. This allows the secondary classification to be based on the combination of the predominant frequency and the amplification factor of the first order peak.

Figure 3 shows the distribution and the classification of the first order peak of the initial state transfer function for 446 kinds of ground. The amplification factor axis is divided into $4(2-3 x, 3-5 x$, $5-10 x$ and more than $10 x$ ) by taking into account that the difference in the amplification factors between the ground becomes much less compared with the initial state because the amplification factor of the first order peak reduces in the finallyconverged state transfer function. The frequency axis is divided into eight, in equal ratio because of the limitation in actuality for the total number of classification. Division according to the difference in predominant frequencies is not considered in the region where the response amplification factor is smallest $(2-3 x)$, because the basement is similar to exposed ground. As the secondary classification, 25 kinds of ground ( $\mathrm{Hw}-1$ to $\mathrm{Hw}-25$ ) are obtained as shown above. The data in the section between Tokyo and Hakata are in 21 kinds.

Figure 4, the initial state transfer functions that belong to the same kinds of ground are superimposed. By taking into consideration that, in the final state, higher order peaks almost diminish and the first order peak becomes dull, it can be recognised that the transfer function that belong to the same kind of ground almost have similar amplification characteristics exists among the separate kinds of ground.

The mark 0 in Figure 3 locates around the centre of each section of the kind of ground and is used as the representative ground of each section for making a model for response analysis. 

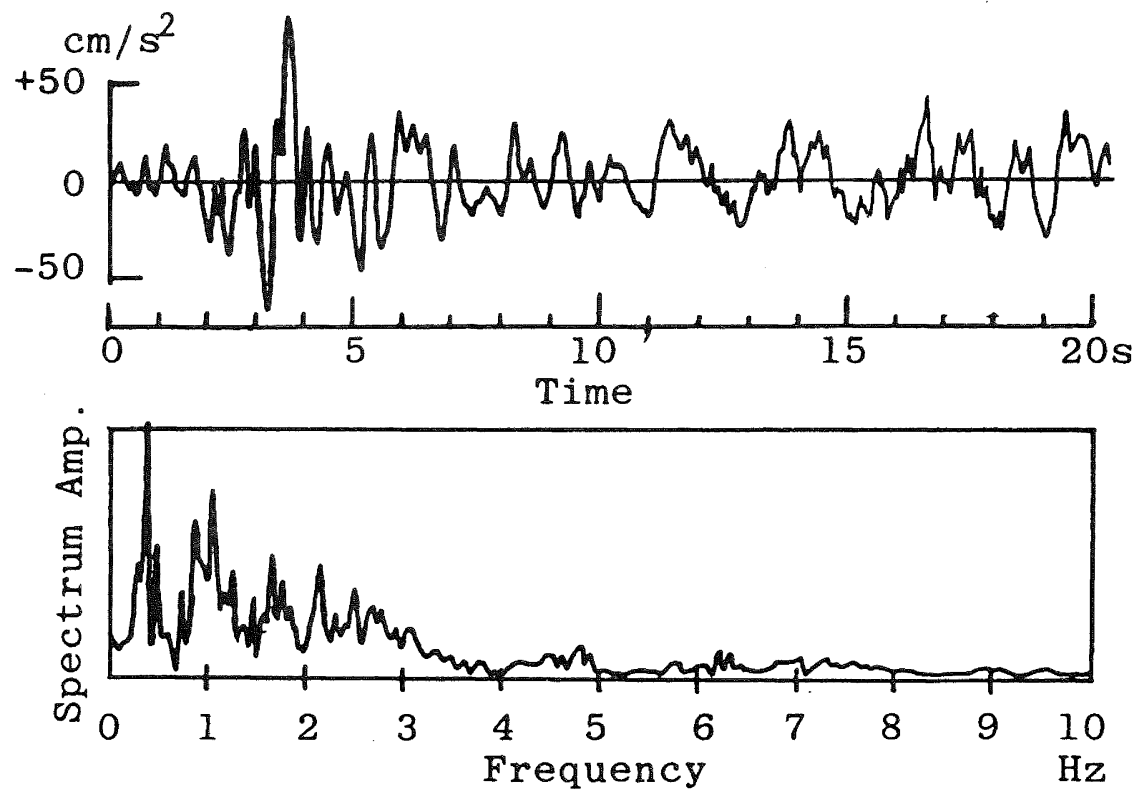

(1) HACHINOHE
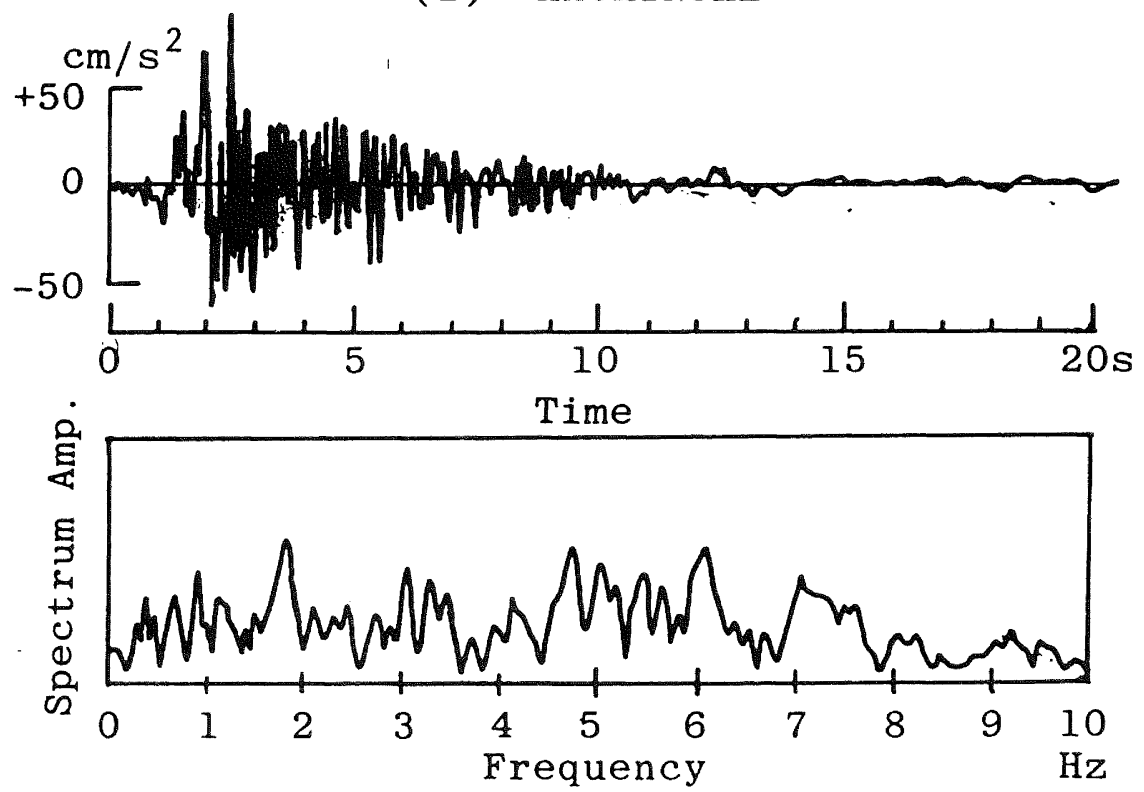

(2) SHIN-KIKUGAWA

Fig. 1 Incident Earthquake Waveforms and their Fourier Spectra Adopted in this Paper.

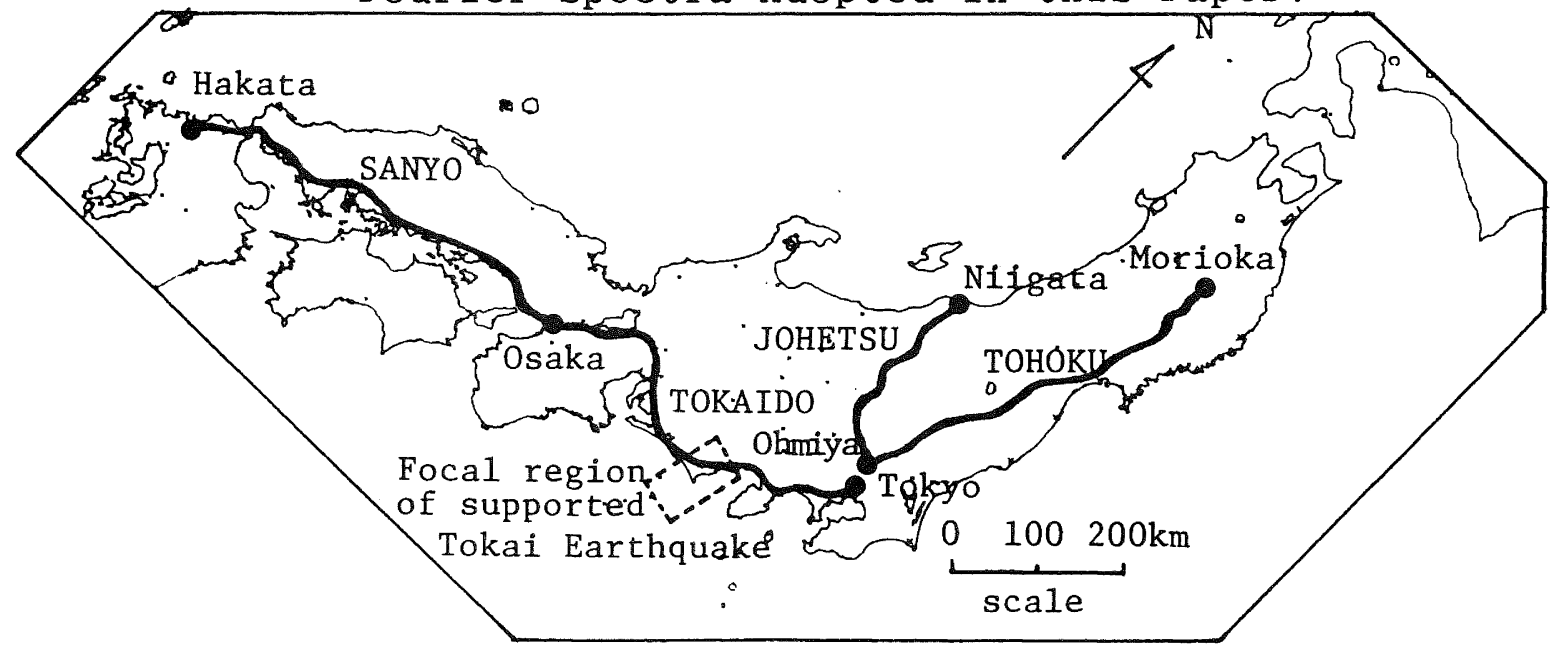

Fig. 2 Shinkansen network in Japan. 


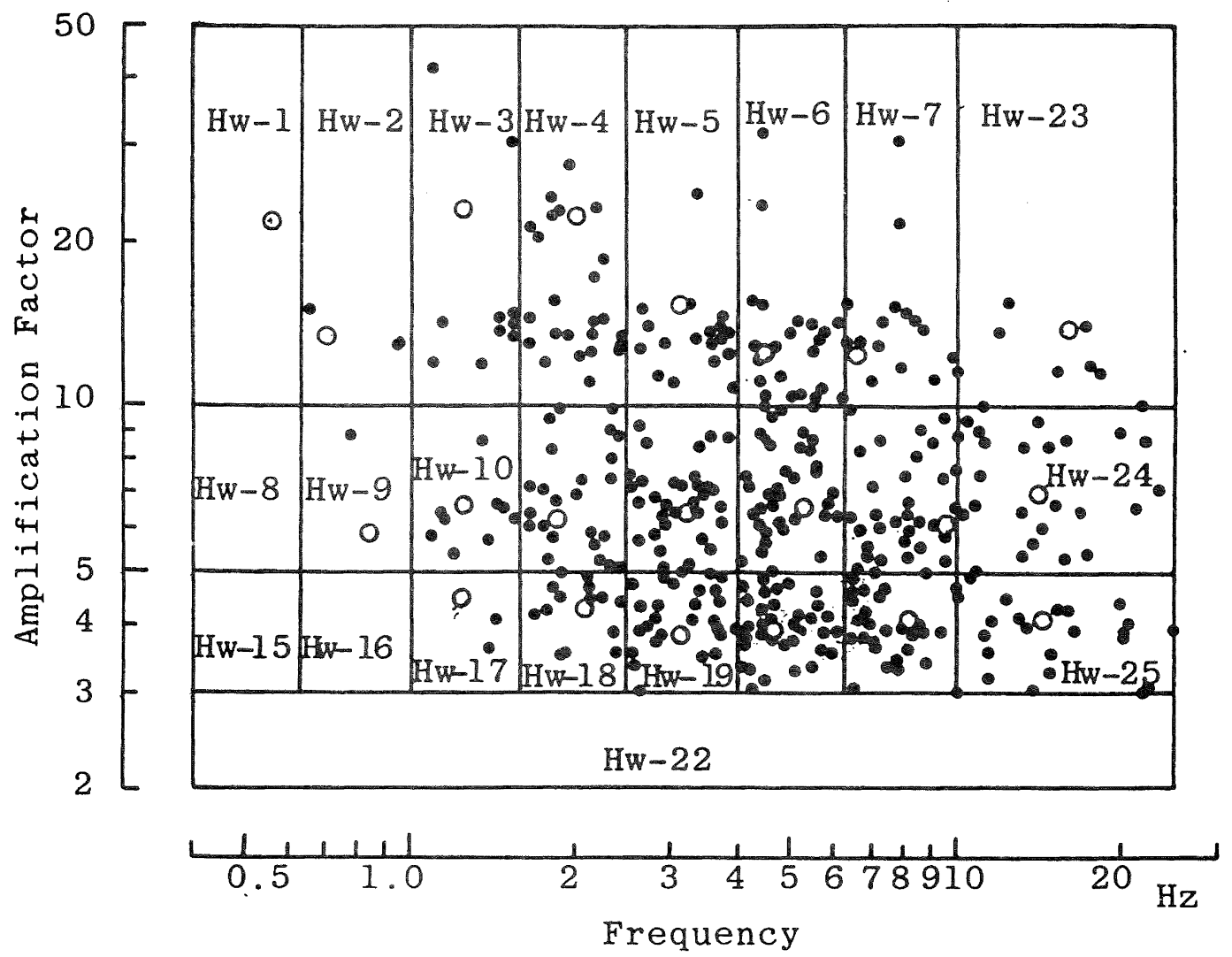

Fig. 3 Classificatio According to First Order Peak

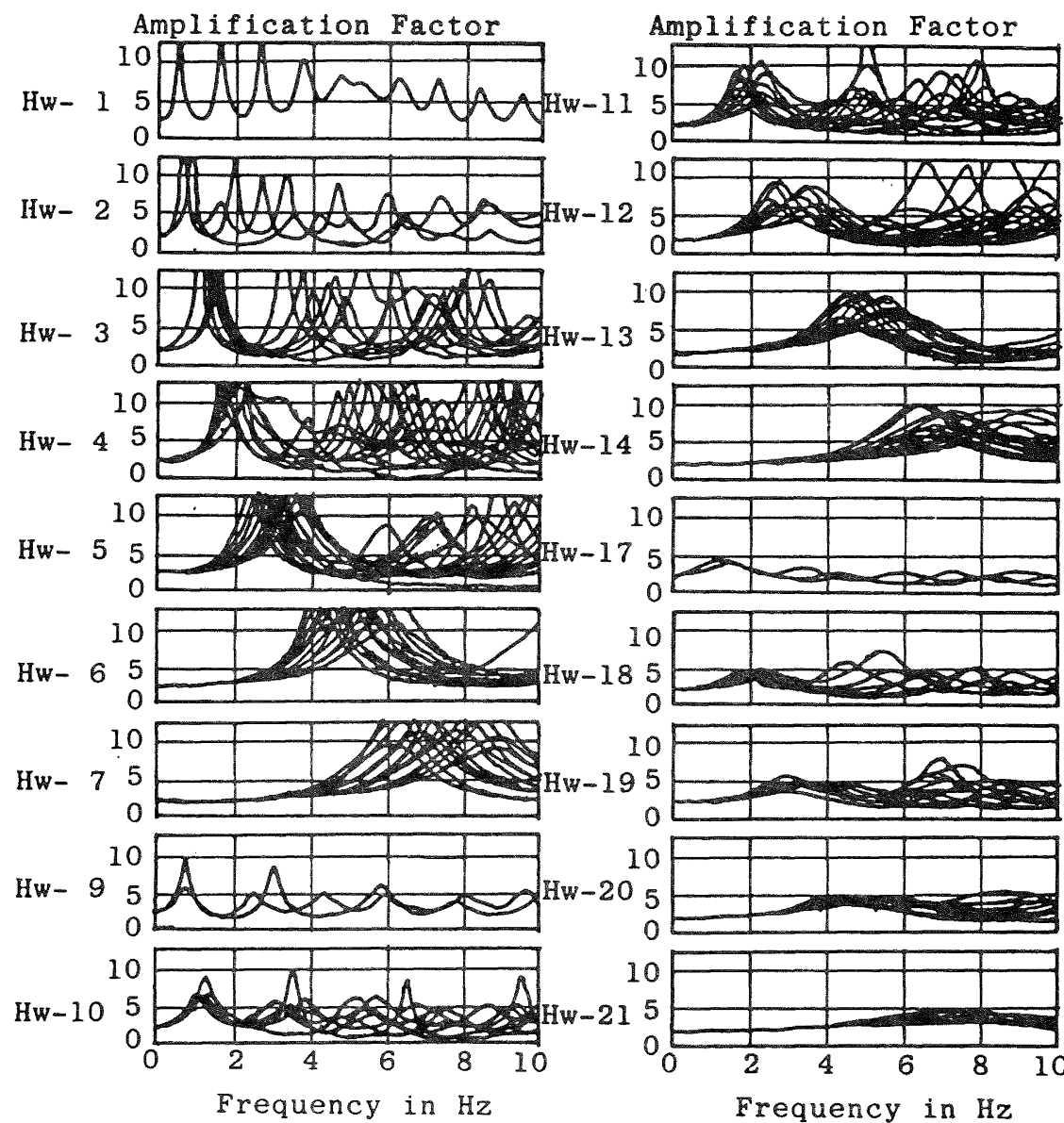

Fig. 4 Secondary Classification of 446 kinds of First Classification Transfer Function of Grounds 
SIMPLE ASSUMPTION METHOD FOR THE FREQUENCY AND AMPLIFICATION FACTOR OF FIRST ORDER PEAK

If the first order peak in the initial state can be found, the classification method described above permits identification.of a specific kind of ground. By using the response curve corresponding to that, the maximum response value can be assumed without any complicated calculation for response. Therefore, a simple assumption method for the first order peak is studied below:

If the velocity structure of horizontal multi-layers is known, the first order predominant frequency $F$ and the amplification factor A can approximately be given by the following equations:

$$
\begin{aligned}
& F=1 /\left(4 \sum_{j=1}^{n-1}\left(H_{j} / V s_{j}\right)\right) \\
& A=2 / R, R=H /\left(V n \cdot \sum_{j=1}^{n-1}\left(H_{j} / V s_{j}\right)\right)
\end{aligned}
$$

where $\mathrm{H}_{j}$ and $\mathrm{Vs}_{j}$ are the thickness and the $S$ wave velocity of the $j$-th layer, respectively, $\mathrm{H}$ is the depth to the basement, Vn is the $S$ wave velocity of the basement layer, and $R$ is the ratio of velocity of basement to the average velocity of surface layer. Equation (1) and equation (2) are given by extending the equations for a 2layer ground to a multi-layer ground on the basis of equivalent layer thickness concept. One thing to be noted is that, as regards amplification factor, an influence due to the difference in density is neglected.

Figure 5 shows the comparison of the assumed values from Equation (1) and equation (2) with the values calculated from the transfer function. They agree very well.

By substituting equation (1) for equation (2), the amplification factor $\mathrm{A}$ is given as a function of predominant frequency F, surface layer depth $\mathrm{H}$ and basement propagation velocity $\mathrm{Vn}$ as shown below:

$$
\mathrm{A}=\mathrm{Vn} /(2 \mathrm{HF})
$$

Since the depth of a surface layer and the propagation velocity at the basement can be supposed from the data obtained at the time of construction, the amplification factor can be assumed from equation (3) by obtaining the first order predominant frequency from the measurement of microtremors. This allows determining the kind of ground.

\section{ASSUMPTION OF RESFONSE CURVE}

Response calculation according to the equivalent linear method was performed with respect to the representative ground of each classification (mark 0 in Figure 3 ). Figure 6 given by Iwasaki and Tatsuoka (5) was used as the strain-dependent curves for shear rigidity and damping factor. The incident waveform on the basement is as described above. As the maximum acceleration at the basement, two values, $150 \mathrm{~cm} / \mathrm{s}^{2}$ and $300 \mathrm{~cm} / \mathrm{s}^{2}$, were adopted to cover the range of maximum accelerations predicted to be observed at the time of a large earthquake. The response curves are given as a relationship of each maximum surface response value with respect to basement acceleration. Average shear strain and shear stress are also determined as surface response values in addition to acceleration, velocity and displacement.

Figure 7 shows the response curves of surface acceleration, velocity and displacement obtained as hyperbolas that pass three points; two points corresponding to the results of response calculation for two basement inputs $\left(150 \mathrm{~cm} / \mathrm{s}^{2}\right.$ and $\left.300 \mathrm{~cm} / \mathrm{s}^{2}\right)$ and origin.

The figure reveals that the acceleration response values are greatly influenced by the kind of ground and also by the incident waveforms of earthquakes. The response values of velocity and displacement are also greatly affected by the incident waveforms of earthquakes, but the influence of the kinds of ground is sometimes little like the "Shin-Kikugawa" wave input. For velocity and displacement, "Hachinohe" wave input gives much response values.

The shear strain and shear stress in the ground are important indices in assuming the movement of the ground such as liquefaction of sand ground and flank flow of clay ground and also in evaluating earthquake-resistance of the foundation of structures. Various approaches are available for determining representative values. In this paper, the distribution of maximum strain and maximum stress up to 5 metres from the surface of the ground is simply averaged. Figure 8 shows the response curves of shear strain and shear stress by interpolating or extrapolating the response values calculated for two kinds of maximum basement acceleration as was performed for surface earthquake motions.

The shear strains in the ground from $\mathrm{Hw}-1$ to $\mathrm{Hw}-4$ are extremely large compared with other ground. This is because it is soft peat. The larger the shear strain is, the smaller the shear rigidity will be, causing the bearing power of the ground to reduce. Therefore, the transformation of the structures constructed on these types of ground will become large. A good example is the large transformation of the Anenuma elevated bridge near Misawa in the Tohoku line, which was caused by the Tokachi-oki earthquake in 1968. It is constructed on soft peat ground. Attention should be paid to soft peat because of the possibility of large transformation of the structures on this type of ground.

\section{GROUND MOTION AT THE TIME OF SUPPOSED} EARTHQUAKE

In the previous paragraphs the classification of surface layer ground and seismic response curve of each ground classified are discussed. As a result, values such as the maximum acceleration, the maximum velocity and the maximum displacement in the surface ground can be estimated if the maximum acceleration of the basement at the time of the supposed earthquake is estimated.

Methods to estimate the maximum acceleration of the basement have been proposed 

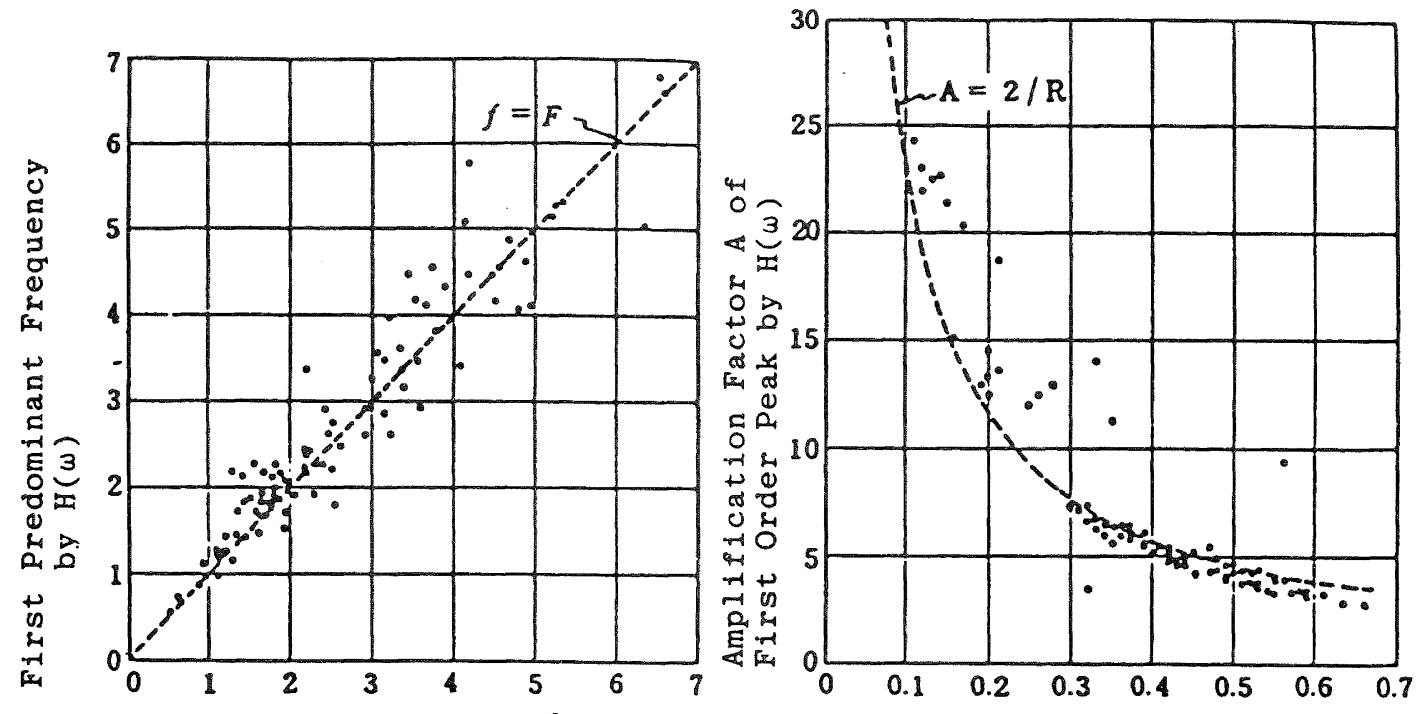

Simply Calculated $\quad F=\frac{1}{4} \cdot \frac{1}{\sum_{j=1}^{n-1}\left(\frac{H_{j}}{V_{s j}}\right)}(\mathrm{Hz})$

(1) Assumption of

Predominant Frequency

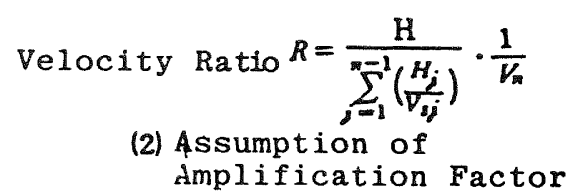

Fig. 5 Assumption of Predominant Frequency and Amplification Factor of Transfer Functions by Simple Calculation

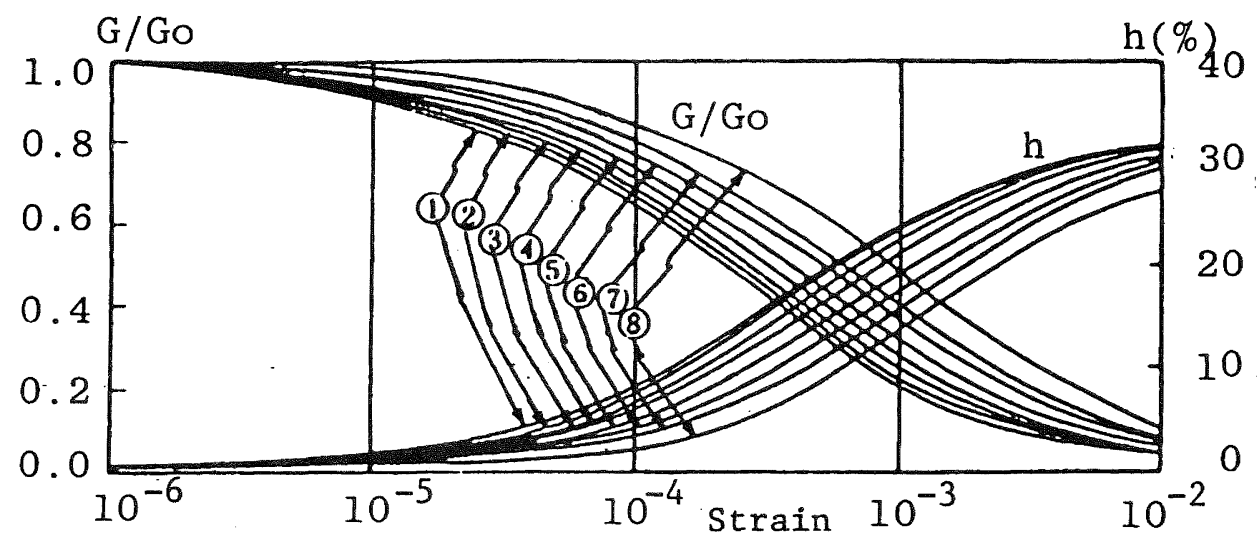

(1) $\mathrm{p}=25,(2) \mathrm{p}=30,(3) \mathrm{p}=50$, , (4) $\mathrm{p}=70$,

( 5$) p=100,(6) p=150,(7) p=200,(8) p=330$. (KPa)

(1) Sand

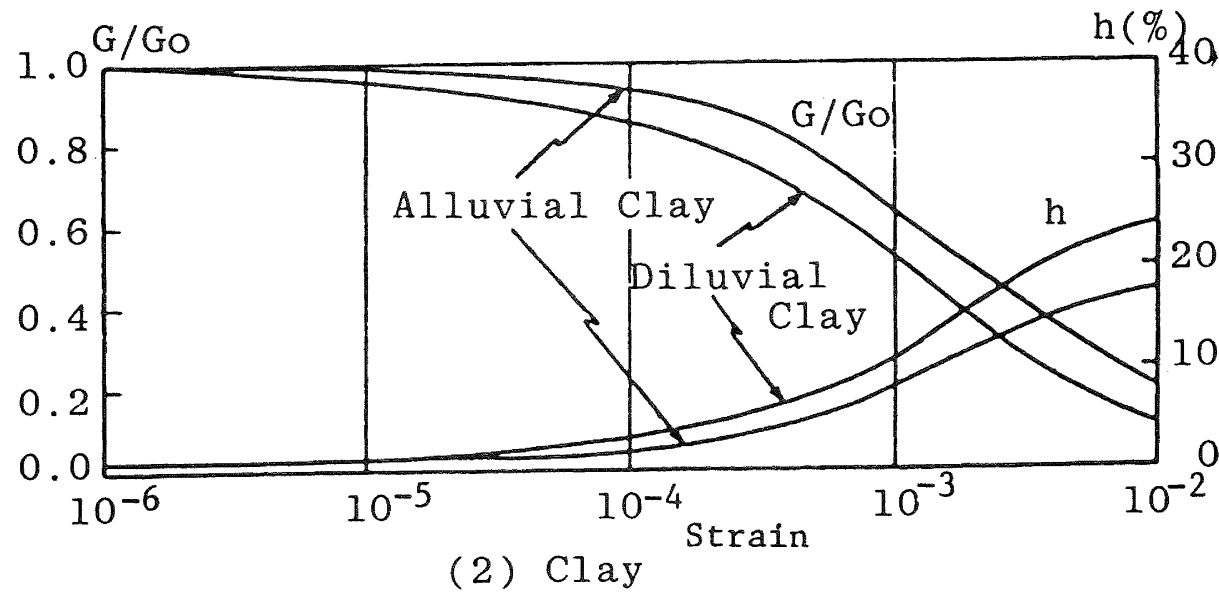

Fig. 6 Strain-Dependent Curves for Rigidity and Damping Factor 

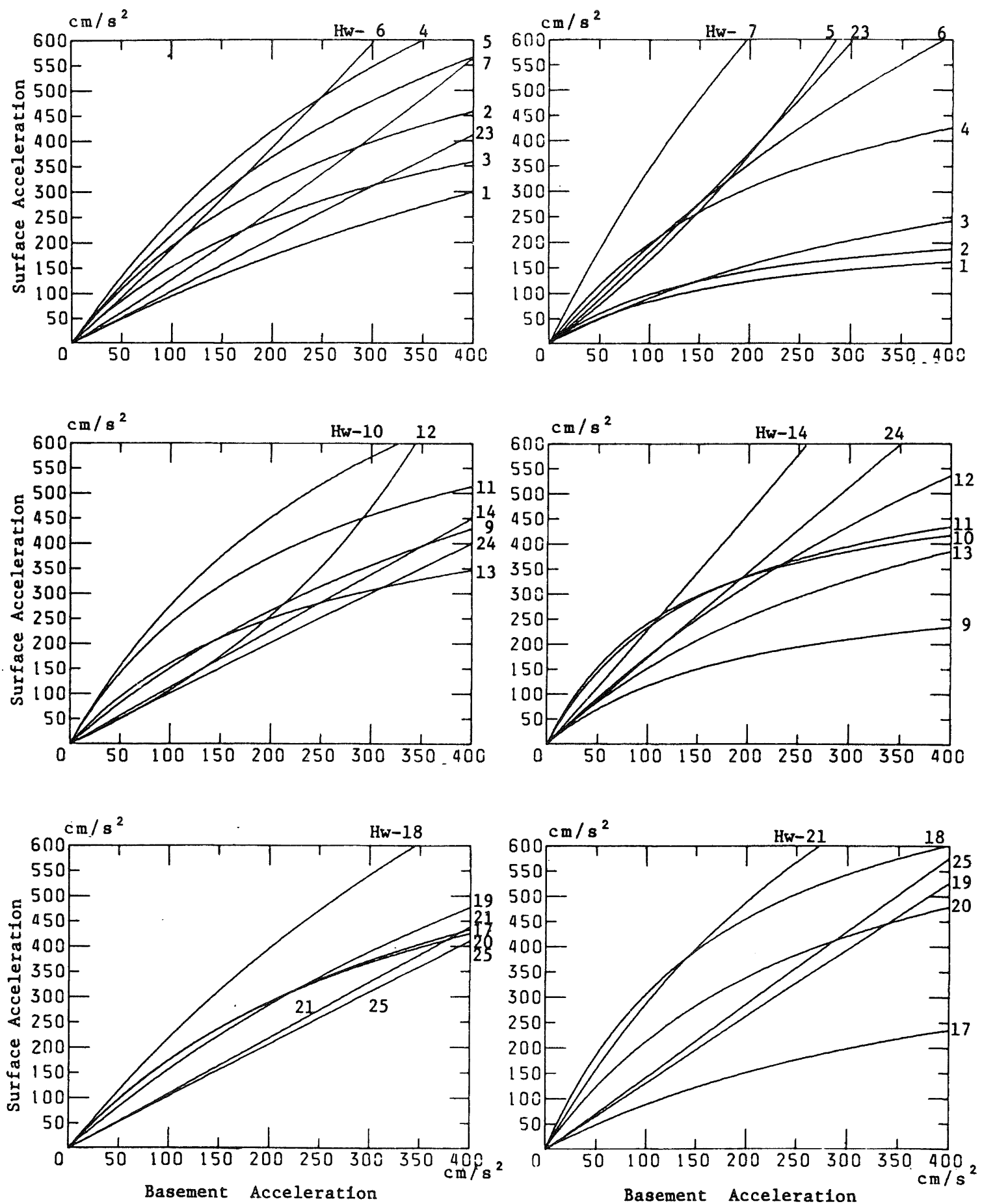

(1) "Hachinohe" Wave Input

(2) "Shin-Kikugawa" Wave Input

Fig. 7(a) Response Acceleration 


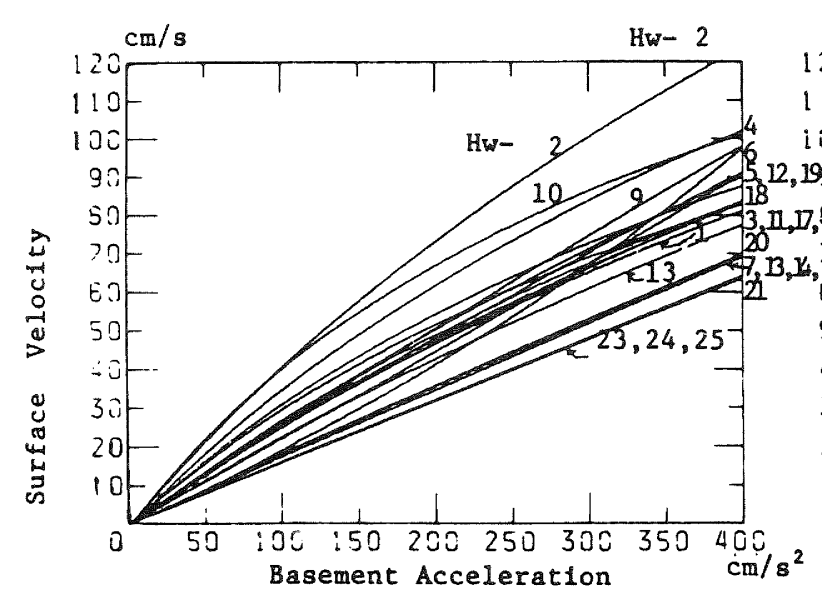

(1) "Hachinohe" Wave Input

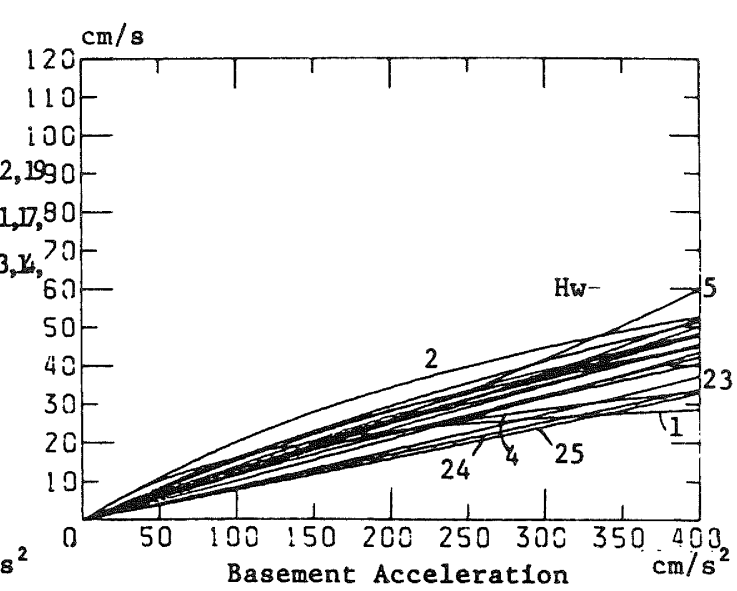

(2) "Shin-Kikugawa" Wave Input

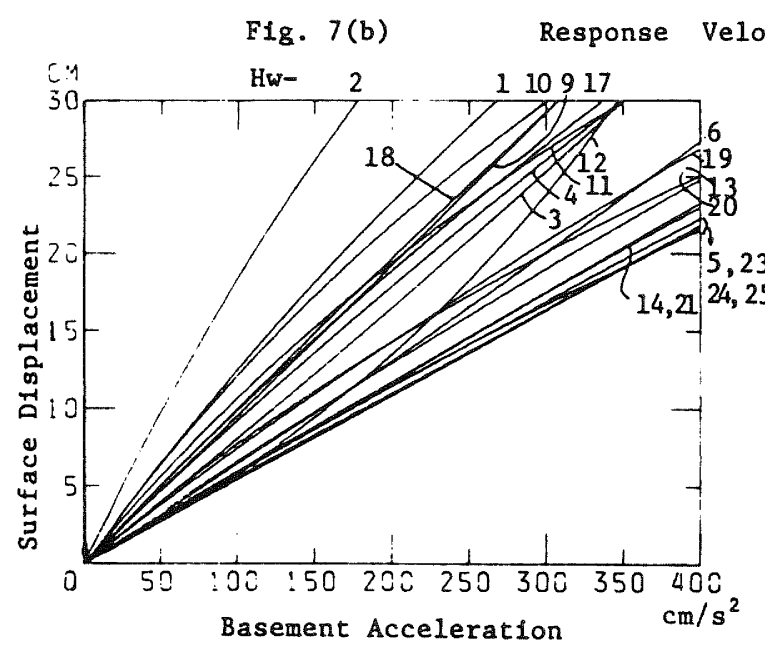

(1) "Hachinohe" Wave Input

Fig. 7(c) Response Displacement

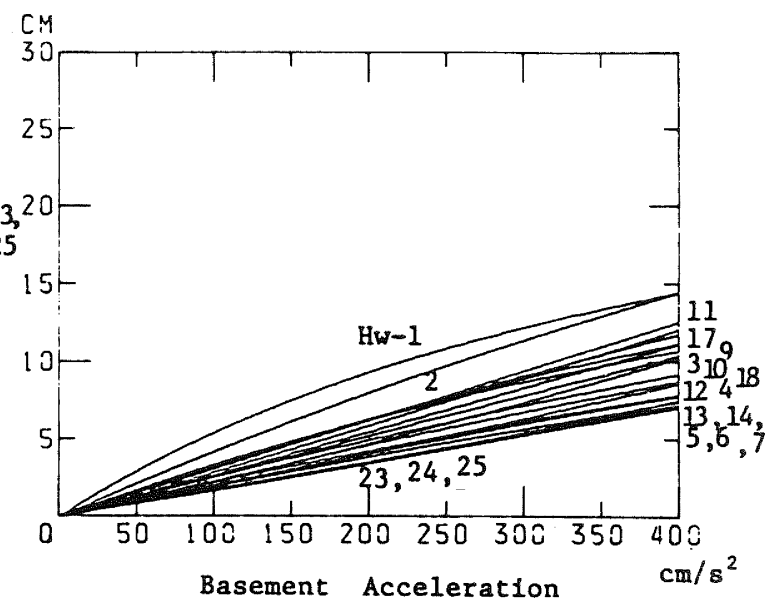

(2) "ShIn-Kikugawa" Wave Input

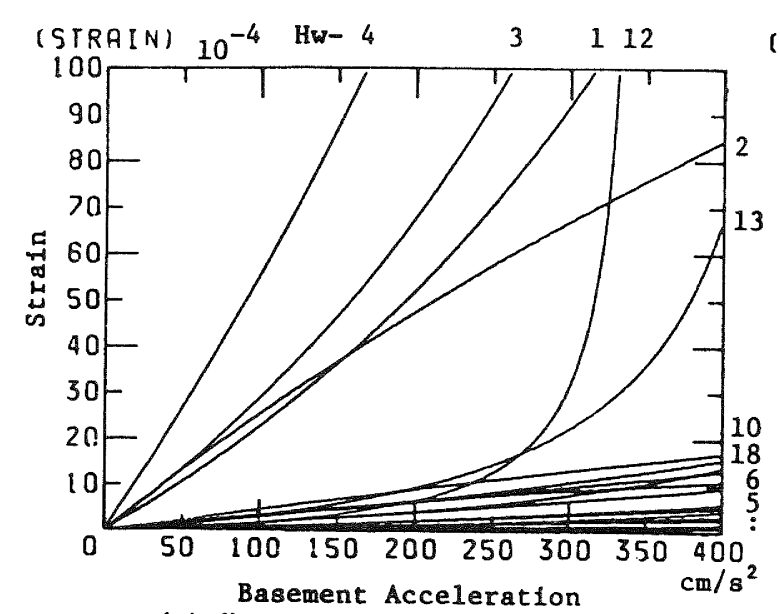

(1) "Hachinohe" Wave Input

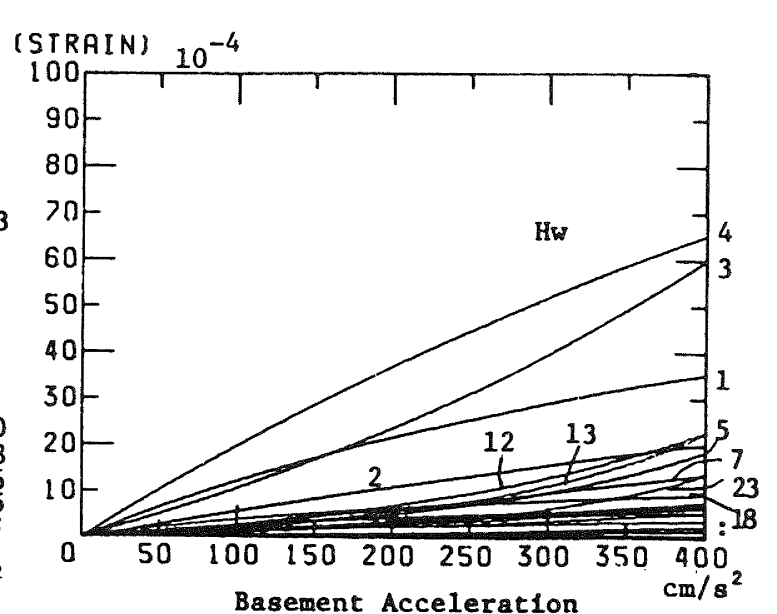

(2) "Sh1n-K1kugawa" Wave Input

Fig 8 (a) Response Strain 
by many researchers. Most of those methods can be summarised in the method to estimate the maximum acceleration $\alpha\left(\mathrm{cm} / \mathrm{s}^{2}\right)$ using the magnitude $\mathrm{M}$ of the earthquake, and the epicentral distance $\Delta(\mathrm{km})$ or hypocentral distance $R(\mathrm{~km})$ as parameters.

For example, the equation proposed by Okamoto and Tamura* (6) which gives rather larger values for distances shorter than $150 \mathrm{~km}$ is used to estimate the earthquake motions of the basement along the

Shinkansen due to the supposed Tokai earthquake.

\section{DAMAGE DUE TO ESTIMATED EARTHQUAKE MOTION}

In order to estimate the damage of structures caused by the earthquake motion, it is necessary to clarify the relation between the scale of the earthquake motion and the degree of the structure damage. We are studying the relation not based on experiments or response analysis but on analysis of past earthquake damage.

Figure 9 shows a procedure to study the relation between the scale of the earthquake motion and the degree of the structure damage.

\section{CLASSIFICATION OF DAMAGE DUE TO PAST EARTHQUAKES}

The damage of structures due to past earthquakes is classified according to degree. Japanese National Railways have a plan to reinforce railway structures to such an extent that transportation can be easily and promptly restored after the earthquake. From this viewpoint, the degree of damage is classified into the following four types:

$(\alpha)$ Severe damage of structures that requires a rather long time for restoration.

(B) Damage of structures that can be repaired soon by emergency measures.

$(\gamma)$ Damage of structures that can be repaired by ordinary maintenance.

( $\delta$ ) No damage.

Detailed standards for classification of damage of earth embankments, backfill for bridge abutments and bridges themselves are shown in Tables 2, 3 and 4 .

\section{ESTIMATION OF THE EARTHQUAKE MOTION AT THE LOCATION OF THE DAMAGED STRUCTURES}

Usually the earthquake force imposed on the damaged structures is not known. So the force is estimated based on the data such as the scale of the earthquake and the epicentral distance.

For the estimation of this force, it is thought reasonable to use a similar method to the one for estimation of the scale of the seismic motion of the earthquake in question. Therefore, the maximum acceleration of the basement is calculated by the equation proposed by okamoto and Tamura (6), and then the maximum

${ }^{*} \log _{10}(\alpha / 1000)=\left(-4.93+0.89 \mathrm{M}-0.043 \mathrm{M}^{2}\right)(\Delta+50) / 100$ acceleration of the surface layer is estimated, taking the amplification characteristics of the surface layer into consideration.

The data of the surface layers available are rather insufficient as shown in Table 5. Hence, the response curves are required for each ground classified. For this purpose, average response curves are drawn, classifying the aforementioned 21 types of ground into the four categories. Then the surface layer acceleration of the relevant points can be obtained.

In some cases, other values such as the maximum velocity and the maximum displacement may be more suitable than the maximum acceleration for expression of the scale of the earthquake motion.

\section{CUMULATIVE CURVE CLASSIFIED BY DEGREE OF EARTHQUAKE DAMAGE}

Cumulative curves are drawn by putting the intensity of the earthquake motion (maximum acceleration) on the axis of abscissa and the percentage of accumulation on the axis of ordinate. Referring to a relevant curve, the degree of the damage can be obtained once the intensity of the earthquake motion is given.

\section{ANALYSIS RESULT}

Damage to railway structures was analysed based on the reports on the damage caused by eight earthquakes as shown in Table 6.

Figures 10, 11 and 12 show the frequency distribution of damage to embankments, bridge abutments and bridge piers respectively. It is noticed that the seismic scale of Japan Meteorological Agency is inappropriate to be related to the four damage types - $\alpha, \beta, \gamma$ and $\delta$ - because actual damage due to earthquakes occurs mostly at the seismic scale V and VI of the Japan Meteorological Agency. Therefore, we decided to estimate the maximum acceleration of the surface layer as described in the previous paragraph in order to study the relation between the acceleration and the degree of damage.

Figures 13 and 14 show the relation between the maximum acceleration of the surface layer and the subsidence of embankments and bridge abutments respective1y. In the figure the data of rather small subsidence are omitted. However, most of such data seem to be located in between the two lines in the figure.

Figures 15 and 16 show the cumulative curves of damage $\alpha, \beta$ and $\gamma$ to embankments and bridge abutments respectively. As to the data of embankments, those of Tokachioki earthquake in 1968 are included. The data of the Tokachi-oki earthquake seem to be different in characteristics from the others because there was a lot of rainfall before the earthquake and the damage was consequently caused by combined effect of both the rainfall and the earthquake. Therefore, the two types of data are shown separately using 0 marks for the Tokachioki earthquake and marks for the others. With this classification, it is understood 


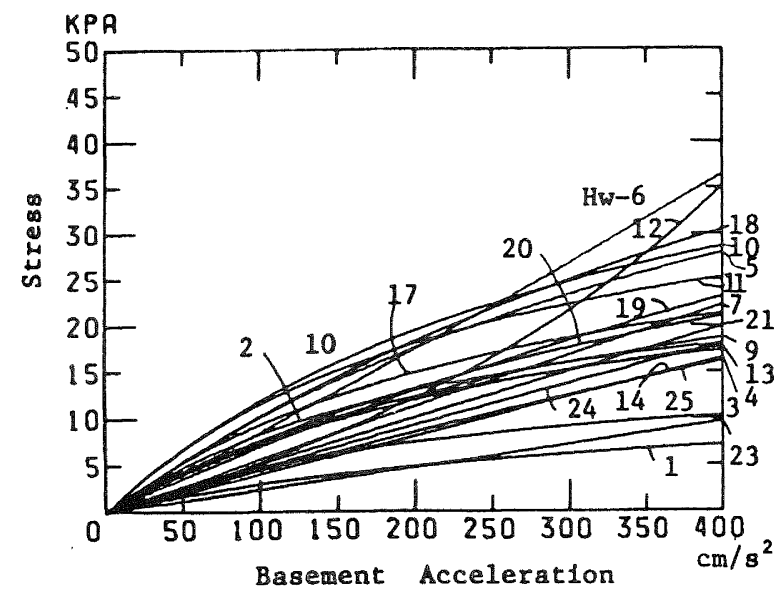

(1) "Hachinohe" Wave Input

F1g. 8(b) Response Stress

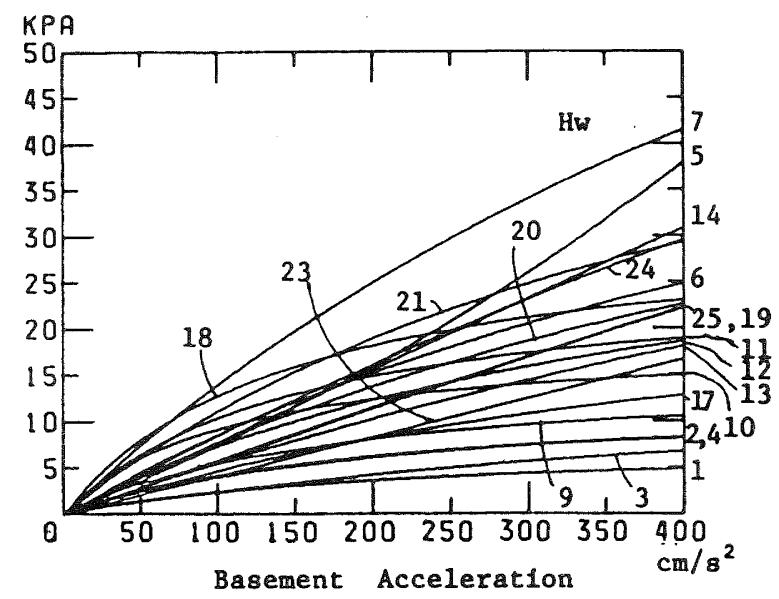

(2) "Shin-Kikugawa" Wave Input

Step (1): Classification of past earthquake damages.<smiles>[C]1[CH]CC1</smiles>
at the damaged structure location.

Step (3): Comparison of the intensity of earthquake motion and the degree of earthquake damage.

Fig. 9 Procedure to study the correlation between the intensity of earthquake motion and the degree of earthquake damage.
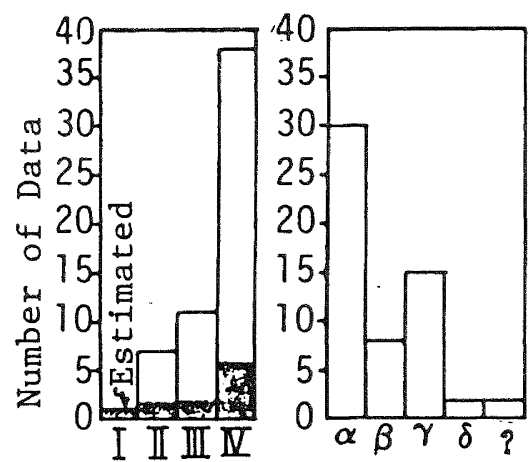

Ggound Types Degree of

Damage

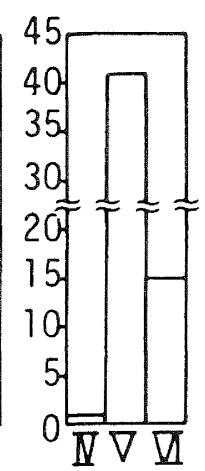

Seismic

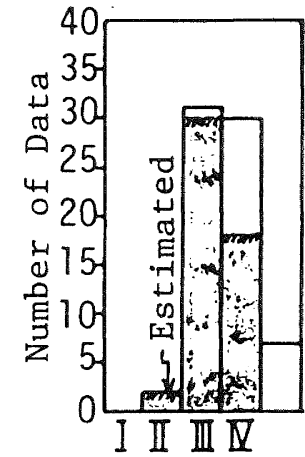

Ground Types

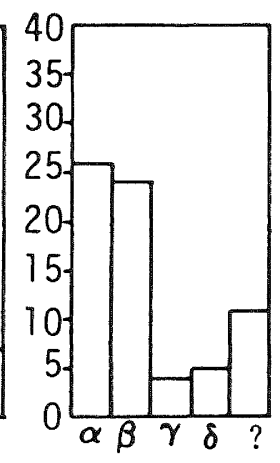

Degree of

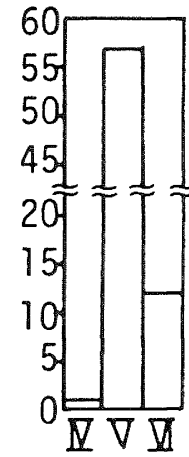

Seismic

Intensity

Fig. 10 Frequency Distribution of Fig. 11 Frequency Distribution of Earthquake Damages to Embankments

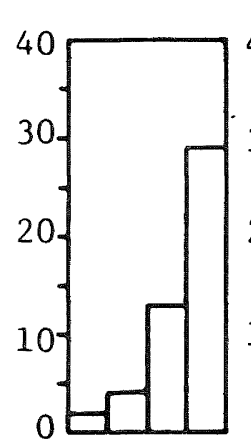

I II JII IV

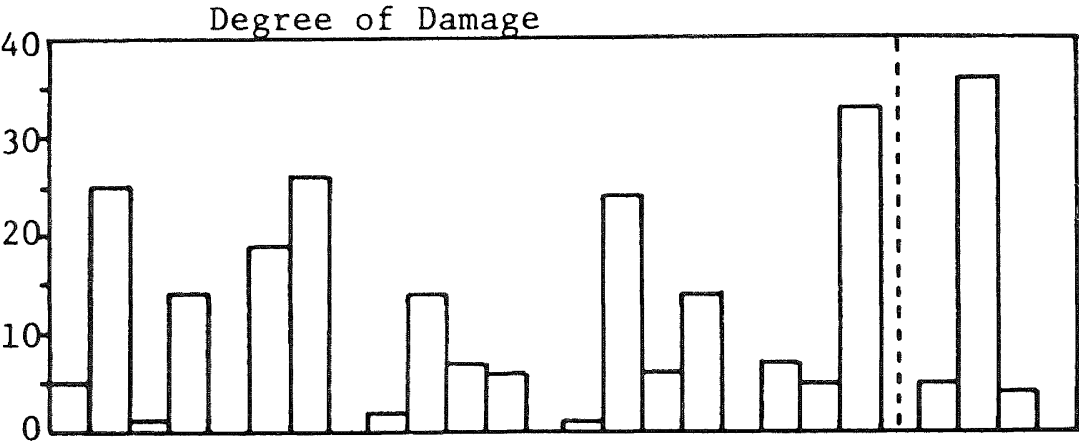

$\alpha \beta \gamma \delta \beta$ $\beta \delta$ $\alpha \beta \gamma \delta$ pier
pirder Support Bridge pier
pirder Support

Fig. 11 Frequency Distribution of
Earthquake Damages to Bridge Abutments Ground Type

$\alpha \beta \gamma$ Wing wall

$B \gamma \delta$ $\alpha \beta \gamma \delta$ Bridge Total abutment

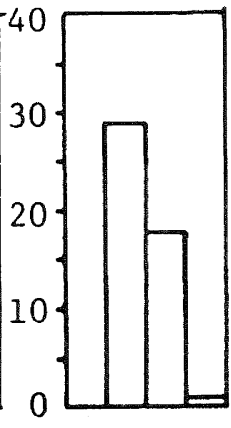

IV V VI ?

Seismic Intensity

Fig. 12 Frequency Distribution of Earthquake Damages to Bridges 


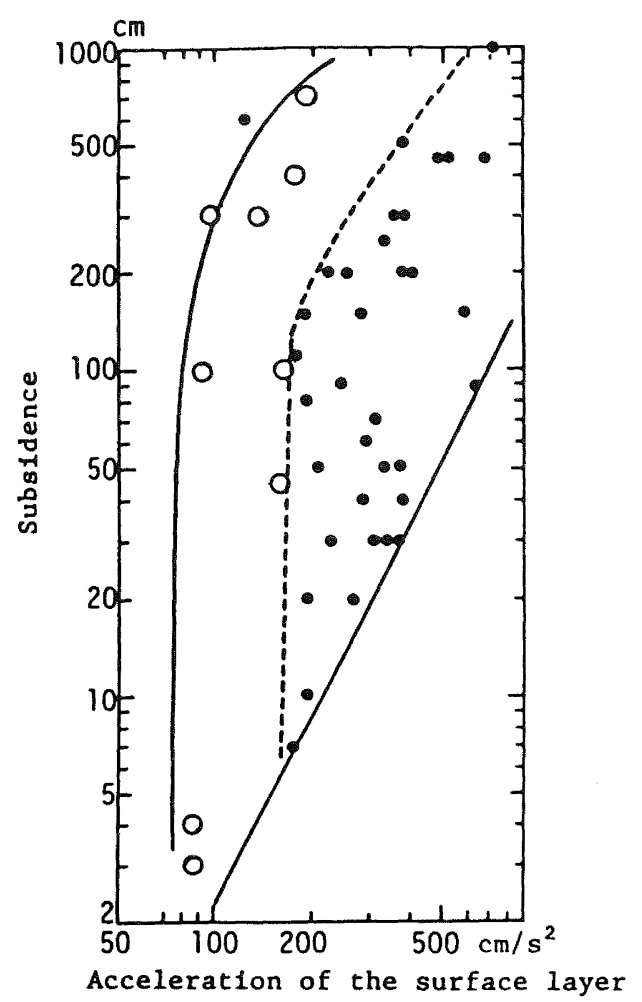

Fig. 13 Relation between amount of Subsidence and Acceleration of the surface layer (as to Embankments)

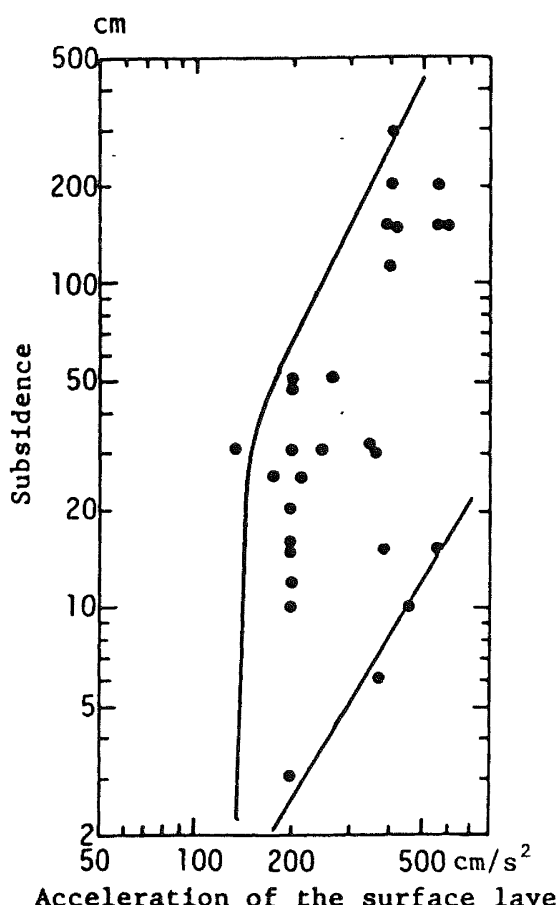

Fig. 14 Relation between amount of Subsidence and Acceleration of the surface layer (as to Bridge Abutments).

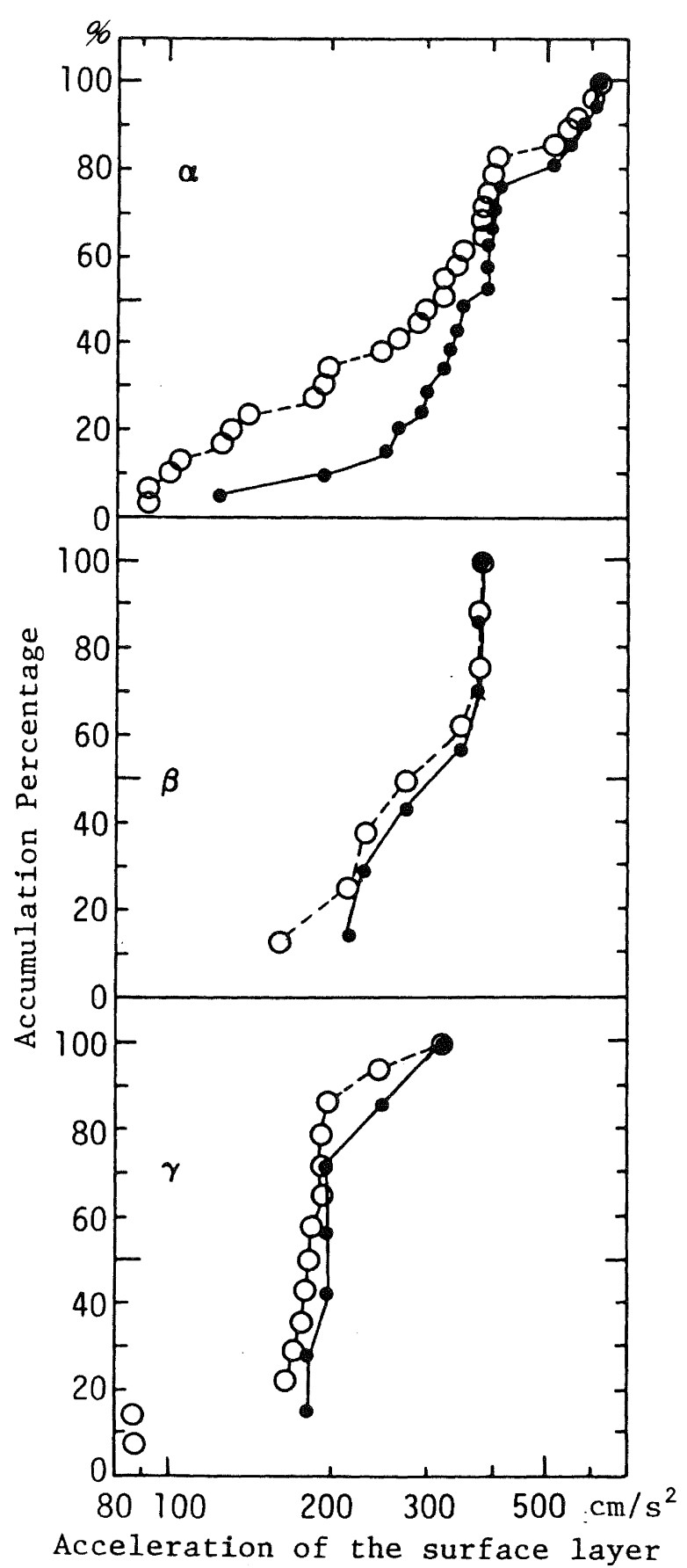

Fig. 15 Cumulative curves of $\alpha, \beta$ and $\gamma$ as to Embankments 
that a smaller acceleration in the surface layer causes damage to embankments when combined with rainfall.

As to the data of bridge abutments, the damage seemingly increases sharply at a certain maximum acceleration of the surface layer (marks). It is because the same types of structures were concentrated at a particular area. To eliminate such a bias of the data, the cumulative curves in Figure 16 are drawn, representing plural data as one point for the case of Niigata City at the time of the Niigata earthquake and for the case of Tohoku cargo railways at the time of the Miyagi-ken-oki earthquake.

For further study, the data of the Tokachi-oki earthquake of 1968 are excluded and the data of the Niigata earthquake and Miyagi-ken-oki earthquake are analysed for the damage to bridge abutments.

It is possible that the damage of $\alpha$ and $\beta$ occurs due to the acceleration larger than the upper limit of the acceleration that causes the damage of $\gamma$, similarly, the damage of $\alpha$ occurs due to the acceleration larger than the upper limit of the acceleration that causes the damage of $\beta$.

As to the possibility of damage of $\alpha$ $\beta, \gamma$ and $\delta$ at a certain acceleration of the surface layer, it is not clearly known due to insufficient data. In the case of embankments and bridge abutments, the degree of damage can be expressed as a continuous quantity and the damage can be roughly estimated, using Figure 13 and 14.

Figure 17 shows the relation between the degree of damage and the surface layer acceleration by illustrating the surface layer accelerations that correspond to frequency accumulations of 10 percent, 50 percent and 90 percent with respect to each damage scale of embankments, abutments of bridge and bridges themselves. The surface layer accelerations corresponding to damage excluding the accumulations of 10 percent and 50 percent of bridge abutments decrease in the order of $\alpha, \beta$ and $\gamma$, as is easily presumed.

The reason why the data for bridge abutments are rather abnormal may be attributed to the fact that the amount of data corresponding to $\gamma$ is small and that the data corresponding to $\beta$ are biased.

Table 7 shows the values corresponding to the frequency accumulations of 50 percent of the damage types $\alpha, \beta$ and $\gamma$ for each structural type in order to approximately give the relation between the seismic accelerations and the structural damage.

To implement earthquake-resistant reinforcement in order to realise immediate restoration of operation, it is necessary to reinforce structures so as to minimise occurrence of. the damage of class $\alpha$. If values of seismic motion corresponding to the frequency accumulation of 90 percent are chosen as the minimum seismic force that causes the damage of class $\alpha$ almost inevitably, the values are defined as 570 $\mathrm{cm} / \mathrm{s}^{2}$ for embankments, $560 \mathrm{~cm} / \mathrm{s}^{2}$ for bridge abutments and $600 \mathrm{~cm} / \mathrm{s}^{2}$ for bridges. In each case, the damage of $\alpha$ will occur almost surely if the acceleration exceeds 600 $\mathrm{cm} / \mathrm{s}^{2}$.

\section{CONCLUSION}

A study was made in this paper on an approach to accurately predict the earthquake ground motions, which affect the safety of railway structures. Urgency to prepare basic data to meet the pressing demand for reinforcement, a certain lat itude was allowed in the study for such indefinite factors as basement incident waveforms because data selectable at the present time was insufficient.

Then the scales which evaluate the damaging characteristics of earthquake motion estimated by this method were experimentarily obtained by analysing the cases of past earthquake damage. The relation between the estimated accelerations and the damage of various structures was briefly investigated.

In order to increase reliability of the method, however, it may be necessary to evaluate the degree of earthquake damage considering the response characteristics of structures and the surface layer seismic movement combination.

By using the proposed method, a prediction is being made for the earthquake motions along the Shinkansen at the time of assumed Tokai earthquake. Also an estimation is being made for the surface responses etc for the earthquakes that have already occurred.

For further stages, we are planning to study the abovementioned problems in order to establish more accurate methods for the estimation of earthquake motion and for evaluation of its damping factor.

\section{ACKNOWLEDGEMENTS}

This study was carried out as a part of earthquake-resistance study project and studying committee for earthquake-resistant reinforcement of railway structures of Japanese National Railways (the chairman is Dr Shunzo Okamoto). Our gratitude is expressed to the chairman and other members for their valuable advice and fruitful discussions.

We are grateful to Mr Akio Saito, technical assistant of the laboratory of structures, Railway Technical Research Institute, Japanese National Railways, for his help to arrange documents of this study.

\section{BIBLIOGRAPHY}

(1) Abe, H, H Wakui and Y Nakamura, "Estimation of Ground Motion due to Strong Earthquakes by Microzoning Method for Shinkansen Railways" (in Japanese), Railway Technical Research Report, No 1216, 1982, 3.

(2) For an example, Kanai, K, T Tanaka and S Yoshizawa, "Comparative Studies of Earthquake Motions on the Ground and Underground (Multiple Reflection 
Problem)",

(3) Tsuchida, H, E Kurata and K Sudo, "Strong Motion Earthquake Records on the 1968 Tokachi-oki Earthquake and its Aftershocks", Technical Note of the Port and Harbour Research Institute, No $80,1969,6$.

(4) Gifu Construction Division,

"Geological Map Along the Tokaido Shinkansen: $45 \mathrm{~km}$ to $263 \mathrm{~km}$ " (in Japanese), 1980,3 .

(5) Iwasaki, T, F Tatsuoka and etc, Reports 107 and 110 (both in Japanese) of Session D-7 in 12th Japan National Conference on Soil Mechanics and Foundation Engineering, 1980, and Report 143 (in Japanese) of Session D-7 in 13th Japan National Conference on Soil Mechanics and Foundation Engineering, 1981.

(6) Okamoto, S, C Tamura and $\mathrm{K}$ Kato, "Maximum Acceleration of Rocky Ground in Earthquakes" (in Japanese), Proceedings of 15 th Japan National Conference on Earthquake Engineering, 1979,7

(7) Japan Road Association, "Design Criteria and Comment for Bridges: V Earthquake Resistant Design", 1980.5.

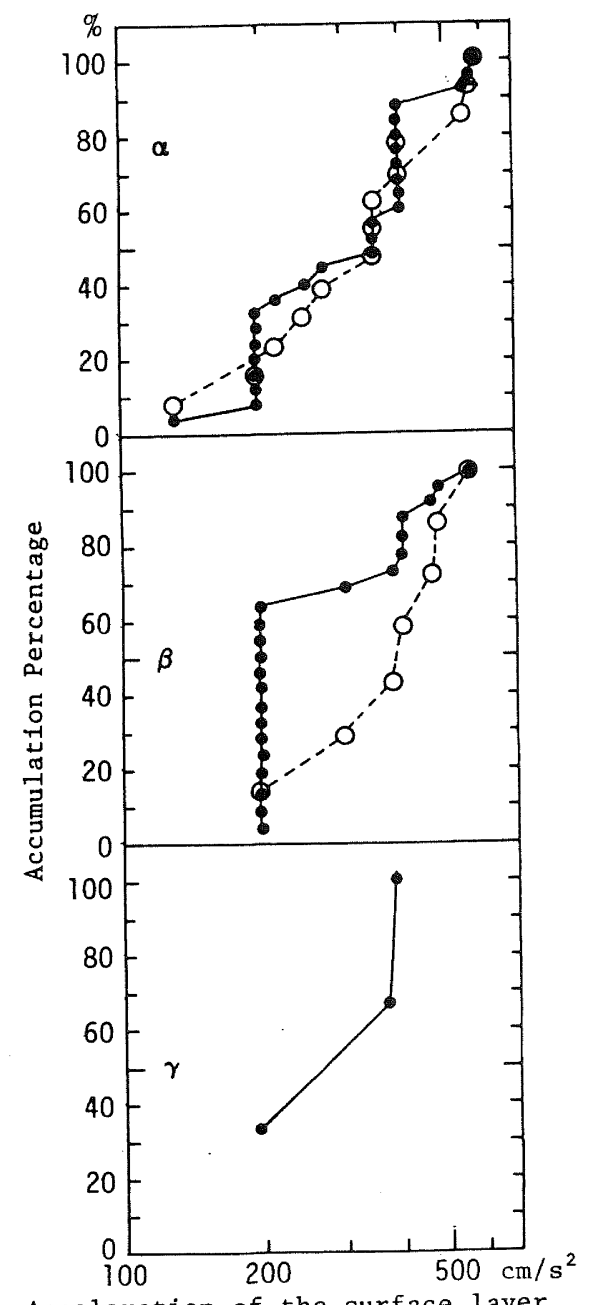

Table 1. Table of Constants for Ground Property and its $\mathrm{N}$ value

\begin{tabular}{|c|c|c|c|c|}
\hline & Geology & $\mathrm{N}$ value & $\begin{array}{l}\text { Vs } \\
(\mathrm{m} / \mathrm{s})\end{array}$ & $\begin{array}{l}\text { Density } \\
(\mathrm{cm} / \mathrm{s})\end{array}$ \\
\hline \multirow{14}{*}{ 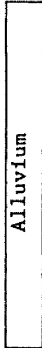 } & \multirow{2}{*}{ Mold } & $\mathrm{N}<3$ & 50 & 1.40 \\
\hline & & $3<\mathrm{N}$ & 70 & 1.50 \\
\hline & \multirow{4}{*}{ Clay } & $N^{<} 5$ & 150 & 1.70 \\
\hline & & $5 \leq \mathrm{N}<10$ & 180 & 1.75 \\
\hline & & $10 \leq \mathrm{N}<20$ & 240 & 1.80 \\
\hline & & $20 \leq \mathrm{N}$ & 300 & 1.85 \\
\hline & \multirow{5}{*}{ Sand } & $\mathrm{N}<10$ & 160 & 1.80 \\
\hline & & $10<N<20$ & 200 & 1.85 \\
\hline & & $20<N<40$ & 250 & 1.95 \\
\hline & & $40 \leq N<50$ & 300 & 2.00 \\
\hline & & $50<\mathrm{N}$ & 500 & 2.00 \\
\hline & \multirow{3}{*}{ Gravel } & $20<N<30$ & 250 & 2.00 \\
\hline & & $30 \leq N<50$ & 350 & 2.00 \\
\hline & & $50 \leq \mathrm{N}$ & 500 & 2.00 \\
\hline \multirow{11}{*}{ 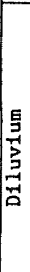 } & \multirow{3}{*}{ Loam } & $N<7$ & 180 & 1.80 \\
\hline & & $7 \leq N<15$ & 250 & 1.80 \\
\hline & & $15<\mathrm{N}$ & 300 & 1.85 \\
\hline & \multirow{3}{*}{ Clay } & $5 \leq \mathrm{N}<10$ & 200 & 1.75 \\
\hline & & $10 \leq \mathbb{N}<20$ & 270 & 1.80 \\
\hline & & $20 \leq \mathrm{N}$ & 340 & 1.80 \\
\hline & \multirow{3}{*}{ Sand } & $20 \leq N<40$ & 270 & 2.00 \\
\hline & & $40 \leq N<50$ & 340 & 2.00 \\
\hline & & $50 \leq \mathrm{N}$ & 500 & 2.00 \\
\hline & Grave1 & $50 \leq \mathrm{N}$ & 500 & 2.00 \\
\hline & \multicolumn{2}{|c|}{ Base Rock } & 900 & 2.50 \\
\hline
\end{tabular}

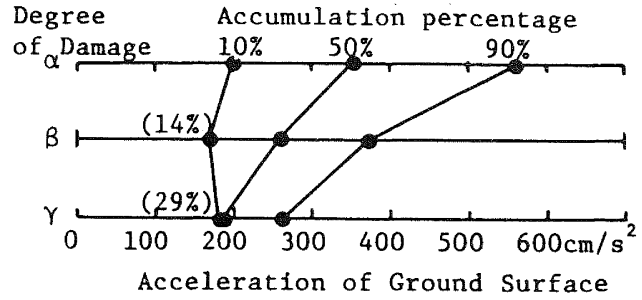

(1) Embankments

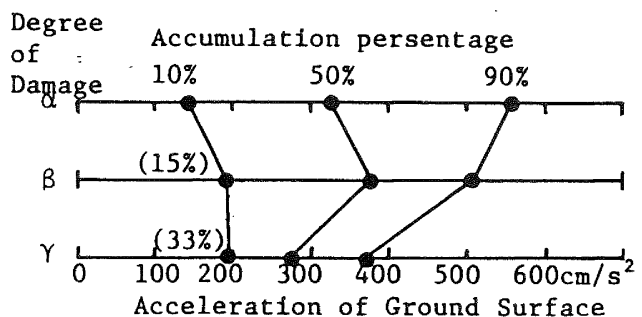

(2) Bridge Abutments

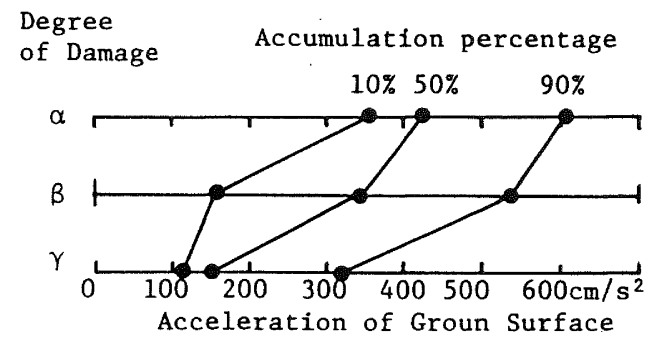

(3) Bridges

Fig. 17 Relation between Accumulation percentage of damage data and Acceleration
Table 2. Evaluation Criteria for the degree of damages of Embankments

\begin{tabular}{|c|c|}
\hline $\begin{array}{l}\text { Degree of } \\
\text { Damage }\end{array}$ & \multicolumn{1}{|c|}{ Evaluation Criteria } \\
\hline$\alpha$ & Subsidence of $50 \mathrm{~cm}$ or more \\
\hline$\beta$ & $\begin{array}{c}\text { Subsidence of } 20 \mathrm{~cm} \text { or more } \\
\text { but less than } 50 \mathrm{~cm}\end{array}$ \\
\hline$\gamma$ & Subsidence less than $20 \mathrm{~cm}$ \\
\hline$\delta$ & No damage \\
\hline
\end{tabular}

Table 3. Evaluation Criteria for the degree of damages of Bridge Abutments

\begin{tabular}{|c|l|}
\hline $\begin{array}{l}\text { Degree of } \\
\text { Damage }\end{array}$ & \multicolumn{1}{|c|}{ Evaluation Criteria } \\
\hline$\alpha$ & $\begin{array}{l}\text { Subsidence of } 20 \mathrm{~cm} \text { or more } \\
\text { or Overturn of abutments }\end{array}$ \\
\hline$\beta$ & $\begin{array}{l}\text { Subsidence of } 10 \mathrm{~cm} \text { or more } \\
\text { or T1lting of abutments }\end{array}$ \\
\hline$\gamma$ & Subsidence less than $10 \mathrm{~cm}$ \\
\hline$\delta$ & No damage \\
\hline
\end{tabular}

Fig. 16 Cumulative curves of $\alpha, \beta$ and $\gamma$ as to Bridge Abutments 


\begin{tabular}{|c|c|c|c|c|c|}
\hline \multicolumn{2}{|c|}{$\begin{array}{c}\text { Degree of } \\
\text { Damage }\end{array}$} & $\alpha$ & B & $\gamma$ & $\delta$ \\
\hline \multicolumn{2}{|c|}{ Damaged Structure } & & & & \multirow{5}{*}{$\begin{array}{l}\text { No damage } \\
\text { or } \\
\text { No remark }\end{array}$} \\
\hline \multirow[t]{2}{*}{$\begin{array}{l}\text { Upper } \\
\text { Structure }\end{array}$} & Girder & * Fall & $\begin{array}{l}\text { * Dispacement } \\
\text { * Collision of } \\
\text { Girders and } \\
\text { Parapet } \\
\text { * Damage at } \\
\text { the End of } \\
\text { Girders }\end{array}$ & * Cracks & \\
\hline & Support & & $\begin{array}{l}\text { * Damage of } \\
\text { Anchor Bolts } \\
\text { * Damage of } \\
\text { Bridge Seats }\end{array}$ & & \\
\hline \multirow[t]{2}{*}{$\begin{array}{l}\text { Sub- } \\
\text { Structure }\end{array}$} & $\begin{array}{l}\text { Bridge } \\
\text { Pier, } \\
\text { Bridge } \\
\text { Abutment }\end{array}$ & * Destruction & $\begin{array}{l}\text { * Subsidence } \\
\text { * Inclination } \\
\text { * Movement } \\
\text { * Cut }\end{array}$ & $\begin{array}{l}\text { * Surface } \\
\text { Separation } \\
\text { * Cracks } \\
\text { * Cracking } \\
\text { of Ground }\end{array}$ & \\
\hline & Wing & & * Destruction & $\begin{array}{l}\text { * Inclination } \\
\text { * Swelling } \\
\text { * Crack }\end{array}$ & \\
\hline
\end{tabular}

Table 5. Ground Classification by Reference (7)

\begin{tabular}{|c|c|c|}
\hline $\begin{array}{l}\text { Ground } \\
\text { Type }\end{array}$ & Comment & $\begin{array}{c}\text { First order Period } \\
\mathrm{Tg} \text { in } \mathrm{s} .\end{array}$ \\
\hline I & $\begin{array}{l}\text { 1) Rocky ground before Tertiary period } \\
\text { 2) Thickness of Dilluvium } * 10 \mathrm{~m}\end{array}$ & $\mathrm{Tg}<0.2$ \\
\hline II & $\begin{array}{l}\text { 1) Thickness of Dilluvium } 210 \mathrm{~m} \\
\text { 2) Thickness of Alluvium** }<10 \mathrm{~m} \\
\end{array}$ & $0.2 \leq \mathrm{Tg}<0.4$ \\
\hline III & $\begin{array}{l}\text { Thickness of Alluvium }<25 \mathrm{~m} \text { and } \\
\text { Thickness of Soft Layer } \star * *>5 \mathrm{~m}\end{array}$ & $0.4 \leq \mathrm{Tg}<0.6$ \\
\hline IV & Ground except abpve & $0.6 \mathrm{sg}$ \\
\hline Note & $\begin{array}{l}\text { *: Including a settled sand layer and } \\
\text { layer in Alluvium. } \\
\text { ** Including a new sediment by a lanc } \\
\text { ** Saturated sand layer (depth }<10 \mathrm{~m}, \\
\text { uniforming coefficient } \mathrm{Uc}<6 \text { and } 0 \\
\text { and Clay or Silt layer (depth }<3 \mathrm{~m} \\
\text { uniaxial compression strength } \mathrm{q}_{\mathrm{u}}<0\end{array}$ & $\begin{array}{l}\text { a settled gravel } \\
\text { dslip, etc.. } \\
\mathrm{N} \text { value } \leq 10, \\
\left..04<\mathrm{D}_{20}<0.5 \mathrm{~mm}\right) \\
\left.\text { and } 2 \mathrm{~kg} / \mathrm{cm}^{2}\right) \\
0.02 \mathrm{l}\end{array}$ \\
\hline
\end{tabular}

Table 6. Number of Data for each earthquake

\begin{tabular}{|c|c|c|c|c|c|c|c|}
\hline \multirow[t]{2}{*}{ No. } & \multirow{2}{*}{$\begin{array}{l}\text { Name of } \\
\text { Earthquake }\end{array}$} & \multirow[t]{2}{*}{ Origin Time } & \multirow[t]{2}{*}{$M$} & \multicolumn{3}{|c|}{ Number of Data } & \multirow[b]{2}{*}{ Total } \\
\hline & & & & Embanments & $\begin{array}{l}\text { Bridge } \\
\text { Abutments }\end{array}$ & Bridges & \\
\hline \multirow{2}{*}{1} & \multirow{2}{*}{ Kanto } & \multirow{2}{*}{1923.9 .1} & \multirow{2}{*}{7.9} & - & 1 & - & 1 \\
\hline & & & & 5 & - & 5 & 10 \\
\hline \multirow{2}{*}{2} & \multirow{2}{*}{ Nankai } & \multirow{2}{*}{1946.12 .21} & \multirow{2}{*}{8.1} & $=$ & - & 1 & 1 \\
\hline & & & & - & - & - & - \\
\hline \multirow{2}{*}{3} & \multirow{2}{*}{ Fukui } & \multirow{2}{*}{1948.6 .28} & \multirow{2}{*}{7.3} & - & 2 & - & 2 \\
\hline & & & & 3 & 2 & 5 & 10 \\
\hline \multirow{2}{*}{4} & \multirow{2}{*}{ Tokachi-oki } & \multirow{2}{*}{ 1952.3. 4} & \multirow{2}{*}{8.1} & - & 5 & - & 5 \\
\hline & & & & 15 & 8 & 11 & 34 \\
\hline \multirow{2}{*}{5} & \multirow{2}{*}{ Niigata } & \multirow{2}{*}{1964.6 .16} & \multirow{2}{*}{7.5} & - & 5 & - & 5 \\
\hline & & & & 2 & 7 & 18 & 27 \\
\hline \multirow{2}{*}{6} & \multirow{2}{*}{ Tokachi-oki } & \multirow{2}{*}{1968.5 .16} & \multirow{2}{*}{7.9} & 1 & 7 & - & 8 \\
\hline & & & & 18 & - & 2 & 22 \\
\hline \multirow[t]{2}{*}{7} & \multirow{2}{*}{$\begin{array}{l}\text { Izu-Oshima- } \\
\text { kinkai }\end{array}$} & \multirow{2}{*}{1978.1 .14} & \multirow{2}{*}{7.0} & - & - & - & - \\
\hline & & & & - & 1 & - & 1 \\
\hline \multirow{2}{*}{8} & Miyagiken- & $1978 \quad 6 \quad 12$ & 74 & 12 & 10 & - & 22 \\
\hline & oki & 1910.0 .12 & 1.4 & 1 & 22 & 6 & 36 \\
\hline (Not & Figures in & the lower & $\mathrm{ne}$ & 13 & 30 & - & 43 \\
\hline & e those rel & lated to Rai & ways & 44 & 40 & 48 & 141 \\
\hline
\end{tabular}

Table 7. Surface layer Accelerations corresponding to each of damages

\begin{tabular}{|l|l|l|}
\hline Structure & $\begin{array}{l}\text { Degree of } \\
\text { Damage }\end{array}$ & $\begin{array}{l}\text { Surface layer } \\
\text { Acceleration at } \\
\text { accumulation } \\
\text { percentage of } \\
50 \%\left(\mathrm{~cm} / \mathrm{s}^{2}\right)\end{array}$ \\
\hline Embankments & $\alpha$ & 350 \\
\cline { 2 - 3 } & $\beta$ & 260 \\
\cline { 2 - 3 } & $\gamma$ & 190 \\
\hline \multirow{3}{*}{$\begin{array}{l}\text { Bbidge } \\
\text { Bridges }\end{array}$} & $\alpha$ & 330 \\
\cline { 2 - 3 } & $\gamma$ & 380 \\
\cline { 2 - 3 } & $\alpha$ & 280 \\
\cline { 2 - 3 } & $\beta$ & 430 \\
\hline \multirow{2}{*}{ As to embankments, data of } \\
\cline { 2 - 3 }
\end{tabular}

Tokachi-oki Earthquake (1968) that are thought to be greatly infuenced by rainfall are excluded. 